\title{
Optional wh-movement is discourse-connected movement in Eastern Cham
}

\author{
Kenneth Baclawski Jr.*
}

\begin{abstract}
Eastern Cham (Austronesian: Vietnam) exhibits apparent optional wh-movement, which shares properties with apparent topicalization. This paper demonstrates that it is not true wh-movement, but discourse connected-, or DC-movement. DC requires a phrase to have an antecedent in a prior sentence and for the antecedent's sentence and the anaphor's sentence to be in a particular discourse structural configuration. Data from complex DP's, specifically partitives, inventory forms, and close appositives demonstrate that DC is a property of referential indices that bind DP's. The incompatibility of wh-phrases and topicality is then explained as the inability of $w h$-phrases to supply referential indices on their own.
\end{abstract}

Keywords. syntax; wh-movement; information structure; pragmatics; Austronesian; Southeast Asian languages

1. Introduction. $\bar{A}$-movement operations to the left periphery seem to exhibit variation as to whether they are optional or obligatory. Wh-movement in languages like English is taken to be obligatory (1a). In situ wh-phrases (setting aside do-support) are typically argued to mark echo questions, with special pragmatic and prosodic properties, labelled 'EQ' below. Topicalization, however, appears to be optional (1b). Moved and in situ topics can have comparable pragmatic interpretations and prosody.

(1) a. $\{$ Which soup $\}$ do you like $\left\{\right.$ which soup EQ $\left._{\mathrm{E}}\right\}$ ?

b. \{THE GAZPACHO $\}$, I like \{THE GAZPACHO $\}$...

In terms of syntax, these movement operations have been distinguished in terms of Agree (cf. Chomsky 2005, 2008). Wh-movement involves an Agree relation between $\mathrm{C}$ and the wh-phrase. Topicalization, or any movement operation with information structural or discourse-related effect, has been argued to be triggered just by an Edge Feature, in the absence of an Agree relation (contra the Cartographic enterprise: Rizzi 1997, among others, who do posit topic features).

\footnotetext{
*My sincere thanks to the Cham people of Ninh Thuận province, Vietnam, especially to Sakaya and Sikhara, without whom this work would not be possible. Any mistakes are my own. Thanks to Peter Jenks and Line Mikkelsen, for their extensive help in the development of this work. Thanks also to Pritty Patel-Grosz, Patrick Grosz, Michael Y. Erlewine, and audiences at UC Santa Cruz, the National University of Singapore, University of Oslo, University of Geneva, the Information Structure in Spoken Language Corpora (ISSLAC3) Workshop, and elsewhere for their helpful feedback and comments. This material is based upon work supported by the Survey of California and Other Indian Languages at UC Berkeley and a National Science Foundation Graduate Research Fellowship under Grant No. DGE-1106400. Any opinion, findings, and conclusions or recommendations expressed in this material are those of the author(s) and do not necessarily reflect the views of the National Science Foundation.

Author: Kenneth Baclawski Jr., University of California, Berkeley (kbaclawski@berkeley.edu).
} 
In some languages, such as Eastern Cham (Austronesian: Vietnam), however, whphrases appear to be optionally $\bar{A}$-moved. ${ }^{1}$ Wh-phrases can be moved to the left periphery (2a), much like topicalization (2b), with only a discourse-related effect. This raises a problem: how can $w$ h-movement be optional if it involves an Agree relation with C? Denham (2000) argues for an analysis with optional projection of CP. Cheng $(1991,1997)$ and others argue through the Clausal Typing Hypothesis that optional whmovement does not exist: the $w h$-phrases must have been moved for some other reason, such as clefting.

a. Hagait hâ daok mbeng? / Hâ daok mbeng hagait?

\{keIt\} hi to? băy \{kocit\}

what 2SG PROG eat what

'What are you eating?'

b. Ing-aong ni kau daok mbeng. / Kau daok mbeng ing-aong ni.

\{Pì Poy ni\} kăw țo? băy \{Piy Poy ni\}

frog this 1SG PROG eat frog this

'This frog, I am eating.'

In this paper, optional wh-movement is argued not to be true wh-movement, but the same movement operation as topicalization (cf. also Mathieu 2004; Pan 2014 for similar analyses). However, this raises a second problem: how can wh-phrases be topicalized? Owing to their interrogative or focal nature (assuming a dichotomy between topic and focus), some have claimed that wh-phrases cannot be topics (e.g. Cable 2008; Cruschina 2012; 158). This paper proposes a solution to this problem with two parts. First, the movement operations in (2a-b) are due not to topicality, but discourse connectedness (DC), a property defined in terms of discourse structure. DC is not incompatible with focus, as it is not an information structural notion. Second, it is shown that DC marks not a whole DP, but its referential index. Wh-phrases can be pied-piped if they have a DC-marked referential index. However, they themselves cannot directly be marked as DC, affirming the intuition that $w h$-phrases should not be referential.

The remainder of this paper is structured as follows. First, Section 2 demonstrates that there is no phrasal wh-movement in Eastern Cham, only covert movement of the Q-particle. Second, locality effects indicate that topicalization and the movement of $w h$-phrases are triggered by the same syntactic feature (Section 3). Section 4 presents a new analysis of both movement operations as discourse connected-, or DC-movement. Section 5 presents data from partitives, and other complex DP's that elucidates the role of referential indices in DC-marking and their interaction with wh-phrases. Section 6 concludes.

\footnotetext{
${ }^{1}$ Data for this paper were collected by the author in Vietnam from 2015-2018 with 33 native speaker consultants born and raised in the Cham villages near Phan Rang, Vietnam. Eastern Cham is an SVO language with little bound morphology. For Eastern Cham examples, the first line represents a Romanization of Cham script known as Rumi. The second, IPA, in line with the Chamic linguistic tradition. Open circles underneath consonants indicates falling, breathy tone or register on the following vowel. The following abbreviations are used CLF $=$ numeral classifier, COMP $=$ complementizer, EMPH $=$ emphatic particle, $\mathrm{FEM}=$ feminine proper noun, $\mathrm{NEG}=$ negation particle, $\mathrm{PROG}=$ progressive aspect marker, ROOT $=$ root modal, $S G=$ singular, $(\mathrm{VN})=$ loanword or code-switching in Vietnamese.
} 
2. Covert Q-movement. Before addressing whether there is optional wh-movement in Eastern Cham, it is necessary to understand the underlying mechanism by which wh-phrases are interpreted. In the basic case, wh-phrases are in situ in Eastern Cham, much like many languages of East and Southeast Asia (cf. Cheng 1991, 1997). Cable (2010) makes a finer-grained distinction between types of $w h$-in situ languages: those that involve covert phrasal movement to $C$ and those that involve movement of just the Q-particle. ${ }^{2}$ At issue is whether wh-phrases show effects of moving at LF to the left periphery.

Eastern Cham wh-phrases do involve some relation with C, as they are sensitive to island constraints. As shown in (3a), an in situ wh-phrase is ungrammatical within a relative clause island, even though no overt movement has occurred. ${ }^{3}$ The same context is grammatical without a wh-phrase (3b). This implies that there exists some Agree relation between $\mathrm{C}$ and $w h$. Note that $w h$-phrases are generally acceptable in situ in embedded clauses.

a. *Hâ blei đồ mbeng baow thei ngap?

*hi plěj dọ bằ po thĕj jă?

2sG buy stuff(VN) eat COMP who make

INTENDED: 'You buy the food that who makes?'

b. Kau blei đồ mbeng baow amaik kau ngap.

kăw plĕj dọ̀ băy po me? kăw yă?

1SG buy stuff(VN) eat COMP mother 1SG make

'I buy the food that my mother makes.'

However, intervention effects demonstrate that in situ wh-phrases cannot covertly move. In (4a), a wh-phrase is under the scope of tha ččj 'only', an intervention effect trigger in Eastern Cham. Kotek $(2014,2017)$ argues that intervention effects arise when a wh-phrase cannot escape the scope of an intervention trigger through overt or covert movement. The ungrammaticality of (4a) indicates that $w h$-phrases have no option to covertly move. As predicted, overt movement is sufficient to obviate intervention (4b).

a. *Sa drei sa-ai Thuận takrâ aia bai halei min?

*tha ç̌̆j laj thù̀n ki Pjæ paj hlej min

only older.sibling Thuận like soup which EMPH

INTENDED: 'Which soup does only Thuận like to eat?'

b. Aia bai halei sa drei sa-ai Thuận takrâ min?

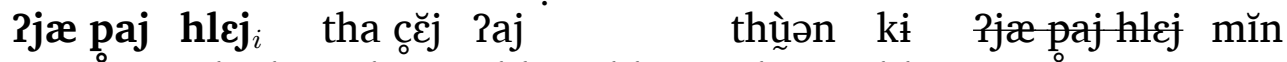
soup which only older.sibling Thuận like EMPH 'Which soup does only Thuận like to eat?'

\footnotetext{
${ }^{2} \mathrm{Cf}$. also true $w h$-in situ languages like Vietnamese (Tsai 2009), where $w h$-phrases have been argued to be interpreted in situ as variables.

${ }^{3}$ The complementizer po is necessary to distinguish between a relative clause reading and a serial verb construction.
} 
Thus, Eastern Cham wh-phrases are not interpreted by covert phrasal movement. They must be interpreted by movement of the Q-particle. It should be noted that this Q-particle is null in Eastern Cham, but perhaps overt in closely related languages like Moken (Baclawski Jr. \& Jenks 2016). Given that in situ wh-phrases are interpreted in this way, it would be surprising for there also to be optional phrasal movement.

3. Locality effects. In this section, apparent wh-movement is shown to be featurally identical to topicalization by locality effects. Both are sensitive to island constraints (5a-b). It should be noted that there is a hanging topic construction, not shown here, that is distinguished by a pause and resumptive pronoun, not seen in the kind of topicalization examined in this paper.

a. *Thei, hâ blei đồ mbeng baow ngap?

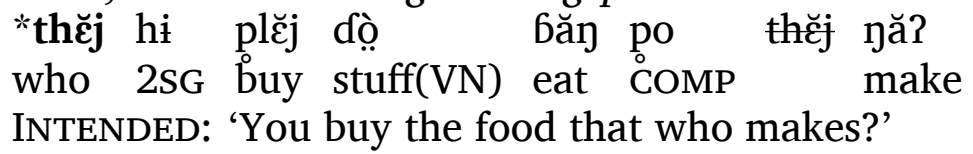

b. *Amaik kau, kau blei đồ mbeng baow ngap.

*mع? kăw kăw plĕj dọ̀ Găn po me? kăw jă? mother 1SG 1SG buy stuff(VN) eat COMP make INTENDED: 'I buy the food that my mother makes.'

Locality effects arise when there are multiple phrases in the left periphery. In general, when there are multiple phrases in the left periphery, the movement chains must be nested in the sense of Pesetsky (1982). (6a) gives an example of nested paths: the

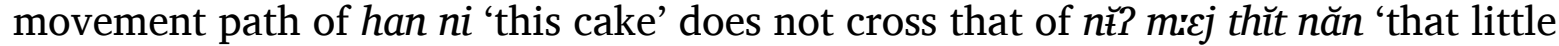
girl'. However, in (6b), the paths cross, and the result is ungrammatical. Baclawski Jr. \& Jenks (2016) analyze the same effect in Moken (Austronesian: Thailand) with multiple probes in the left periphery.

a. Ahar ni anâk kumei sit nan Thuận da-a mai mbeng.

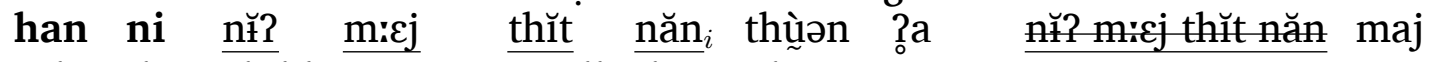
cake this child woman small that Thuận invite $\bar{c}$ come

băy han ni

eat

'This cake, Thuận invited that little girl to come eat.'

b. *Anâk kumei sit nan ahar ni Thuận da-a mai mbeng.

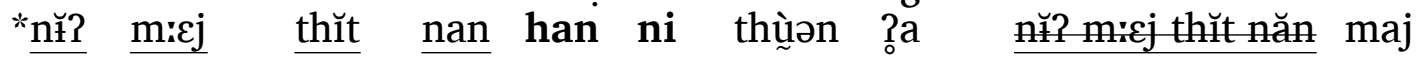
child woman small that cake this Thuận invite come

băy han ni

eat

INTENDED: 'This cake, Thuận invited that little girl to come eat.'

When there is one topic and one wh-phrase in the left periphery, the same effect holds. If the paths are nested (7a), the result is grammatical. If they are crossed (7b), it is strongly and consistently ungrammatical. This follows if there are two probes in the left periphery both searching for the same feature. 
(7) a. Ahar ni anâk kumei sit halei Thuận da-a maj mbeng?

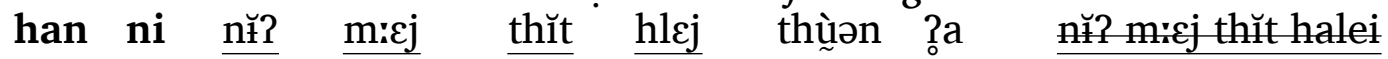
cake this child woman small which Thuận invite maj băy han ni come eat 'Which little girl did Thuận invite to come eat this cake?'

b. “Anâk kumei sit nan ahar halei Thuận da-a maj mbeng?

*n̆̆? m:cj thĭt năn han hlej thừən ?ọa nŭ? micj thĭt năn child woman small that cake which Thuận invite

maj băy han halei come eat

INTENDED: 'Which cake did Thuận invite that little girl to come eat?'

One hypothesis is that these probes are searching for a general $\bar{A}$-feature in the sense of Aravind (2017, 2018), and others. Such an $\bar{A}$-feature could include topic and wh. Aravind (2017) uses these general features to explain similar path containment effects in English. A general Ā-feature would not account for Eastern Cham, though, because in situ $w h$-phrases do not intervene on movement of topics or other wh-phrases (8a-b). ${ }^{4}$ Wh-phrases, in situ or not, are taken to be assigned a general A-feature, and in other languages such as English and Malayalam, they do in fact intervene on movement (Aravind 2017). Something else is driving the movement in Eastern Cham.

a. Ahar ni Thuân da-a thei mai mbeng.

han ni thừəon ?a thĕj maj băy han ni

cake this Thuận invite who come eat

'Who did Thuận invite to come eat this cake?'

b. Hagait, Thuận da-a thei mai mbeng?

ket thừən ?a thĕj maj băy keket

what Thuận invite who come eat

'Who did Thuận invite to come eat what?'

Topicalization and the movement of wh-phrases in Eastern Cham are instances of the same movement operation from a featural standpoint. Both are driven by the same syntactic feature. However, this raises a problem. If that feature is [topic], it would require $w h$-phrases to be able to be marked as topical. This is problematic under certain views of information structure. Cruschina (2012), and others argue that there is an incompatibility between topic and focus or interrogativity.

4. Discourse connectedness. This section begins to answer how wh-phrases can appear to be topical by redefining both categories. What seems to be topicalization is in fact discourse connected- or DC-movement, and what appears to be optional wh-movement is DC-movement of a wh-phrase. Discourse connectedness, first observed by López (2009) (as [+anaphora]) for clitic right-dislocation in Catalan, has two components (9).

\footnotetext{
${ }^{4}$ Note that these same facts obtain for movement out of embedded clauses. Superiority effects do not obtain in local or non-local contexts (cf. Baclawski Jr. \& Jenks 2016 on Moken).
} 
First, the phrase in question must be a discourse anaphor, an anaphor whose antecedent is in a prior sentence in the discourse. Second, the antecedent's sentence must discourse subordinate the anaphor's sentence (10).

(9) DISCOURSE CONNECTEDNESS (DC): For antecedent $x \in$ sentence $\phi$ and anaphor $y$ $\in$ sentence $\psi, y$ is DC iff $\phi$ discourse subordinates $\psi$

(10) DISCOURSE SUBORDINATION: Sentence $\phi$ discourse subordinates sentence $\psi$ if $\psi$ is interpreted as a subpart of the focus space denoted by $\phi$, but not vice versa

Discourse subordination was first defined in terms of focus spaces and attention states by Grosz \& Sidner (1986) (as 'dominance'). Subsequently, it has been defined in terms of embedded eventualities (cf. Asher \& Lascarides 2003; Asher \& Vieu 2005 in Segmented Discourse Representation Theory), or in terms of discourse intentions (cf. Mann \& Thompson 1988 in Rhetorical Structure Theory, as 'nucleus-satellite relations'). Informally, it involves two sentences, or discourse units, one of which elaborates on the other and leaves it open for future discussion. Why should discourse subordination be relevant to an anaphor? According to the Right-Frontier Constraint (Polanyi 1985; Webber 1988), discourse subordination is one of multiple conditions that render an antecedent accessible for anaphora. Discourse connectedness restricts discourse anaphora to just this one condition, resulting in a stronger, more specific anaphoric relation.

To illustrate, consider the discourse in (11a-b). (11a) contains an antecedent 'frog'. (11b) has an anaphor, identical to its antecedent. That anaphor can be DC-moved, because the two sentences are in a subordinating discourse relation. One elaborates upon the other. The same anaphoric relation is present in $\left(b^{\prime}\right)$. However, DC-movement is illicit, because the sentence is not in a subordinating relation. Instead, it is interpreted as a separate event.

(11) a. CONTEXT: 'Look at Thuận cook frog ${ }_{i}$ '

b. Ing-aong nyu ngap bingi ralo.

$\left\{\right.$ Pì $\left.2 \mathfrak{y}_{i}\right\}$ nu yă? \{\} y:i lo frog 3.ANIM make be.delicious very

'He makes[cooks] frog very well [LIT: deliciously].' $\quad \checkmark$ Subordination(a,b)

$\mathrm{b}^{\prime}$. Sơn ngap ing-aong hu o.

$\{\#\}$ srn thằw jă? $\left\{\right.$ Pin $\left.\operatorname{Poy}_{i}\right\} \quad \mathrm{O}$

Sơn know.NEG make frog NEG

'Sơn does not know how to make[cook] frog.' XSubordination(a,b')

The same holds for $w h$-phrases. The antecedent in brackets in (12a) defines a set of two pots. Both $\left(12 \mathrm{~b}, \mathrm{~b}^{\prime}\right)$ have anaphors that refer to that set in the form of $w h$-phrases. However, only (12b) is in a subordinating discourse relation with (12a), as it is interpreted within the same event. By contrast, $\left(12 b^{\prime}\right)$ is interpreted as a separate event, and DC-movement is infelicitous. 
(12) a. ConteXt: 'Look at my father boil [one pot of fish and one pot of frog $]_{i}$ ',

b. Urak ni, gaok hagait ong nan daok ngap nan?

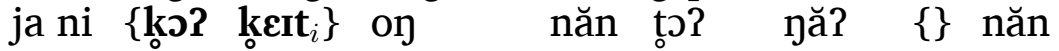

now pot what old.man that PROG make that

'Now, what pot is that old man making [working on]?' $\checkmark$ Subordination(a,b)

$\mathrm{b}^{\prime}$. Urak ni, ong nan daok mbeng gaok hagait nan?

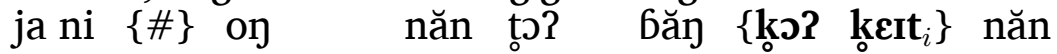

now old.man that PROG eat pot what that

'Now, what pot is that old man eating?'

XSubordination $\left(\mathrm{a}, \mathrm{b}^{\prime}\right)$

Topicality does not directly account for the pattern above. If topic is defined in terms of old information (e.g. Chafe 1976), it is insufficient to distinguish between the (b) and ( $\left.b^{\prime}\right)$ sentences. Both have identical prior information states (i.e. (a)). Topic is also defined in terms of aboutness, as in the phrase around which a sentence is organized (e.g. Reinhart 1981). Some analyses preclude wh-phrases from being topics altogether, which would not account for the Eastern Cham data. ${ }^{5}$ Otherwise, both the (b) and $\left(b^{\prime}\right)$ sentences can be construed as being about the set of pots (cf. Casielles-Suarez 2004; 23; López 2009; 27 for other arguments against old information and aboutness topic). Nevertheless, aboutness has some explanatory power: only the (b) examples can be paraphrased with 'As for X...', at least in the English glosses (cf. Reinhart 1981). Discourse connectedness provides a concrete way to encode the pattern above, which can be embedded within broader theories of discourse (i.e. Segmented Discourse Representation Theory or Rhetorical Structure Theory).

Encoding anaphoric relations between discourse moves has some precedent in the literature. According to Büring (2003), Constant (2014), and others, contrastive topics require a discourse anaphoric relation within a complex Question Under Discussion (QUD). There must be an antecedent and an anaphor within a subpart, or strategy, to answer a broader QUD. This is comparable to discourse connectedness, as both involve leaving a prior sentence open for further discussion. However, these accounts of CT are more restricted: they require open Questions Under Discussion and an element of contrast. In Eastern Cham DC-movement, contrast is never present, and open QUD's are not required. ${ }^{6}$ Other models of discourse have posited less restricted relations between sentences. Onea $(2013,2016)$ posits that certain phenomena are sensitive to Potential Questions, any question that is compatible with the presuppositions of the prior sentence. Discourse connectedness is more restricted, requiring discourse subordination, though an analysis could be construced within the Potential Question framework, especially following Onea (2016), which integrates Potential Questions with Segmented Discourse Representation Theory.

As detailed above, discourse connectedness is defined in terms of discourse structure, not pure topicality. DC is not necessarily incompatible with $w h$-phrases. It is widely accepted that wh-phrases, especially discourse-, or D-linked wh-phrases, can have

\footnotetext{
${ }^{5}$ López (2009) also restricts the ability of wh-phrases to be assigned [+anaphora] due to the fact that they cannot be clitic right-dislocated in Catalan.

${ }^{6} \mathrm{Cf}$. Baclawski Jr. (2018) on the realization of contrastive topic in Eastern Cham.
} 
discourse antecedents in some way (cf. Pesetsky 1987; Comorovski 1996). DC simply requires that a phrase have an antecedent and their respective sentences have a certain type of relation in the discourse. The following section examines these antecedents in more detail.

5. Referential indices. This section examines complex DP's, such as partitives, and finds that only referential indices are DC-marked. It has been argued that definite DP's of various kinds contain syntactic instantiations of their domain restrictions. These domain restrictions are generally filled by indices supplied by the context. For example, Patel-Grosz \& Grosz (2017) propose the structures in Figure 1 for personal and demonstrative pronouns (cf. also Schwarz 2009). Demonstrative pronouns are distinguished from personal pronouns by an additional DP projection, which merges a referential index from the context set, here, 7, for example.

Figure 1: Pronoun structure, as per Patel-Grosz \& Grosz (2017; (7-8))

(a) Personal pronoun

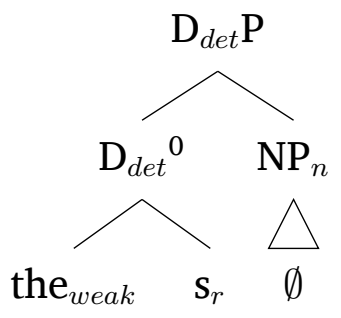

(b) Demonstrative pronoun

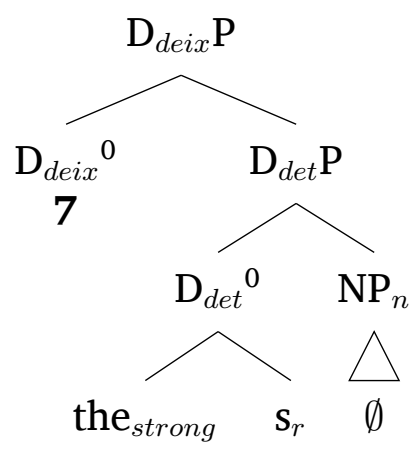

With this in mind, it has been argued that overt pronouns or other DP's can specify the reference of the referential indices. As evidenced by Huang et al. $(2009 ; 298)$ and Jenks (2018), close appositives such as (13a) in Mandarin Chinese are structurally singular DP's in which the element on the left overly marks the referential index that binds the definite DP on the right. Eastern Cham has a similar close appositive (13b). Note that the root modal $h u$ is clause-final and has scope over the predicate.
a. wo xihuan [Zhangsan, Lisi na ji-ge guai haizi $]_{D P}$. I like Zhangsan Lisi those several-CLF good children 'I like those good kids like Zhangsan and Lisi.'

MANDARIN (Huang et al. 2009; 299)

b. Hâ da-a Phú saong Hoa, dua urang nan hu.

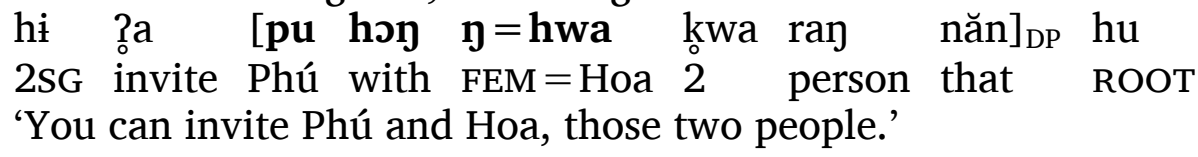

Two additional constructions have similar properties. Partitives are formed in Eastern Cham by moving a noun that originates lower in the DP to a higher position (14a). The noun that moves corresponds with the one that marks the antecedent set in the 
c. *Pa-aok ni, ajuh abaoh, kau blei.

$* 2 \breve{P}$ ni cuh poh kăw plej [?ว̆2 ni çuh pəh]
mango this 7 CLF 1 sG buy

INTENDED: 'Seven of these mangoes, I bought.'

Second, the referential index DP conversely cannot consist of a wh-phrase. In general, a partitive can contain a wh-phrase, as in (17a). However, the referential index DP cannot (17b). Note that the question is askable when prompted in elicitation, and the gloss in English is grammatical.

a. Hâ blei pa-aok ni hadom ki?

hi plej [?ॅ̆? ni tom ki?]

2SG buy mango this how.many $\mathrm{kg}$

'How many kilograms of these mangoes did you buy?'

b. "Hâ blei abaoh kayau halei sa ki?

hi plej [poh zaw hlej tha ki?]

2SG buy fruit which one $\mathrm{kg}$

INTENDED: 'Which fruit did you buy one kilogram of?'

These facts can be explained if it is the referential index that is marked as discourse connected, not the whole DP. That is why only the referential index DP can be DCmoved. This also accounts for the incompatibility of $w h$-phrases and referentiality: wh-phrases can be DC-moved, if they are pied-piped by a DC-marked referential index; however, they cannot supply that referential index on their own.

6. Conclusion. What seems to be optional wh-movement in Eastern Cham is in fact discourse connected-, or DC-movement. This result upholds the Clausal Typing Hypothesis and provides a way to account for movement operations that target both whphrases and topics. Both can be DC-moved so long as they are discourse anaphors in a particular discourse structure configuration. Yet, there remains an incompatibility: DC targets referential indices, and $w h$-phrases cannot supply referential indices themselves. Instead, they can be pied-piped by a DC-marked index.

Many questions remain for future research. First, even though discourse connectedness restricts the contexts DC-movement can occur in, the movement operation remains optional in some sense. Is this true optionality, perhaps susceptible to Optimality Theoretic constraints, or only apparently optional, the result of different derivations that coincidentally receive similar interpretations (cf. Müller 2003 on pseudo-optionality)? Second, this paper has only presented a syntactic analysis of DC; how is DC interpreted, and how can it mark sets of alternatives like wh-phrases? Third, how is DC comparable to other information structural notions like D-linking? Finally, how is DC-movement of wh-phrases possible in languages like Eastern Cham, but not in others like Catalan? 


\section{References}

Aravind, Athulya. 2017. Ā-interactions and feature geometries. In Claire Halpert, Hadas Kotek \& Coppe van Urk (eds.), A Pesky Set: Papers for David Pesetsky, 333-342. MIT Press.

Aravind, Athulya. 2018. Licensing long-distance wh-in-situ in Malayalam. Natural Language \& Linguistic Theory 36. 1-43. https://doi.org/10.1007/s11049-017-9371-2.

Asher, Nicholas \& Alex Lascarides. 2003. Logics of Conversation. Cambridge University Press.

Asher, Nicholas \& Laure Vieu. 2005. Subordinating and coordinating discourse relations. Lingua 115. 591-610. https://dx.doi.org/10.1016/j.lingua.2003.09.017.

Baclawski Jr., Kenneth. 2018. Contrastive topic in Eastern Cham. Berkeley Formal Papers in Linguistics 1(1). https://escholarship.org/uc/item/3hp0s863.

Baclawski Jr., Kenneth \& Peter Jenks. 2016. Clefts and Anti-Superiority in Moken. Journal of the Southeast Asian Linguistics Society 9. 81-96. https:// openresearch-repository.anu.edu.au/handle/1885/105175.

Büring, Daniel. 2003. On d-trees, beans, and b-accents. Linguistics and Philosophy 26. 511-546.

Cable, Seth. 2008. Wh-fronting in Hungarian is not focus fronting. Manuscript. ling.auf. net/lingbuzz/000674/v1.pdf.

Cable, Seth. 2010. The Grammar of Q. Oxford University Press.

Casielles-Suarez, Eugenia. 2004. The syntax-information structure interface: Evidence from Spanish and English. Routledge.

Chafe, Wallace L. 1976. Givenness, contrastiveness, definiteness, subjects, topics and point of view. In Charles N. Li (ed.), Subject and topic, 25-55. New York: Academic Press.

Cheng, Lisa L.S. 1991. On the typology of wh-questions: MIT dissertation.

Cheng, Lisa L.S. 1997. On the typology of wh-questions. New York: Garland. Chomsky,

Noam. 2005. Three factors in language design. Linguistic Inquiry 36. 1-22. https://doi.org/10.1162/0024389052993655.

Chomsky, Noam. 2008. On phases. In Robert Freidin, Carlos P. Otero \& Maria Luisa Zubizarreta (eds.), Foundational issues in linguis-tic theory: Essays in honor of Jean-Roger Vergnaud, 133-166. MIT Press. https://doi.org/10.7551/ mitpress/9780262062787.001.0001.

Comorovski, Ileana. 1996. Interrogative phrases and the syntax-semantics interface. Springer.

Constant, Noah. 2014. Contrastive topic: Meanings and realizations: University of Massachusetts, Amherst dissertation.

Cruschina, Silvio. 2012. Discourse-related features and functional projections. Oxford University Press.

Denham, Kristin E. 2000. Optional wh-movement in Babine-Witsuwit'en. Natural Language \& Linguistic Theory 18. 199-251.

Enç, Mürvet. 1991. The semantics of specificity. Linguistic Inquiry 22(1). 1-25. 
Grosz, Barbara \& Candace Sidner. 1986. Attention, intentions, and the structure of discourse. Computational Linguistics 12(3). 174-204.

Huang, James C.-T., Y.-H. Audrey Li \& Yafei Li. 2009. The syntax of Chinese. Cambridge Unviersity Press.

Jenks, Peter. 2018. Articulated definiteness without articles. Linguistic Inquiry 49(3). 501-536. https://doi.org/10.1162/ling_a_00280.

Kotek, Hadas. 2014. Composing questions: MIT dissertation.

Kotek, Hadas. 2017. Dissociating intervention effects from superiority in English whquestions. The Linguistic Review 34(2). 397-417. https://doi.org/10.1515/tlr2017-0005.

López, Luis. 2009. A derivational syntax for information structure. Oxford University Press.

P. Mann, William \& Sandra Thompson. 1988. Rhetorical structure theory: Toward a functional theory of text organization. Text 8(3). 243-281. https://doi.org/10.1515/ text.1.1988.8.3.243.

Mathieu, Eric. 2004. The mapping of form and interpretation: The case of optional whmovement in French. Lingua 114(9-10). 1090-1132. https://doi.org/10.1016/j.lingua.2003.07.002.

Müller, Gereon. 2003. Optionality in optimality-theoretic syntax. In Lisa Cheng \& Rint Sybesma (eds.), The Second Glot International State-of-the-Article Book, 289-322. Walter de Gruyter. https://doi.org/10.1515/9783110890952.289.

Onea, Edgar. 2013. Potential questions in discourse and grammar: University of Göttingen Habilitation thesis.

Onea, Edgar. 2016. Potential questions at the semantics-pragmatics interface. Brill.

Pan, Victor Junnan. 2014. Wh-ex-situ in Mandarin Chinese: Mapping between information structure and split CP. Linguistic Analysis 39. 371-413.

Patel-Grosz, Pritty \& Patrick Grosz. 2017. Revisiting pronominal typology. Linguistic Inquiry 48(2). 259-297. https://doi.org/10.1162/ling_a_00243.

Pesetsky, David. 1982. Paths and categories: MIT dissertation.

Pesetsky, David. 1987. Wh-in-situ: Movement and unselective binding. In Eric J. Reuland \& Alice G.B. ter Meulen (eds.), The representation of (in)definiteness. 98-129. Cambridge, MA: MIT Press.

Polanyi, Livia. 1985. A theory of discourse structure and discourse coherence. Papers from the General Session at the 21st Regional Meeting of the Chicago Linguistics Society $(C L S)$.

Reinhart, Tanya. 1981. Pragmatics and linguistics: An analysis of sentence topics. Philosophica 27. 53-94.

Rizzi, Luigi. 1997. The fine structure of the left periphery. In Liliane Haegeman (ed.), Elements of grammar: A handbook of generative syntax. 281-327. Kluwer. https://doi.org/10.1007/978-94-011-5420-8_7.

Schwarz, Florian. 2009. Two Types of Definites in Natural Language. University of Massachusetts, Amherst dissertation.

Simpson, Andrew. 2005. Classifiers and DP structure in Southeast Asia. In 
Guglielmo Cinque \& Richard Kayne (eds.), The Oxford handbook of comparative syntax, 806-838. Oxford University Press. https://doi.org/10.1093/ oxfordhb/9780195136517.001.0001.

Tsai, Cheng-Yu Edwin. 2009. Wh-dependency in Vietnamese and the syntax of wh-in-situ: National Tsing Hua University dissertation.

Wang, Chyan-an Arthur. 2007. Sluicing and resumption. In Proceedings of the 37th North East Linguistic Society, 239-252. Amherst, MA: GLSA.

Webber, Bonnie L. 1988. Discourse deixis: Reference to discourse segments. In Proceedings of the 26th Annual Meeting on Association for Computational Linguistics, 113122. https://doi.org/10.3115/982023.982037. 